\title{
Interferon Alpha
}

National Cancer Institute

\section{Source}

National Cancer Institute. Interferon Alpha. NCI Thesaurus. Code C20494.

A class of interferon (leukocyte interferon) produced predominantly by B lymphocytes.

Located in a cluster on 9p22 there are at least 13 functional genes and 1 pseudogene. 